lence until they attracted attention, the result of which rould have been, thet idiopathic diabetes would have been found to be a rather common, instead of, as it is, a comparatively rare disease.

Applying these observations to the present case, we see that, by a treatment directed to allay irritability of the stomach, and by a carefully but not rigidly restricted diet, well-marked diabetic condition of the urine, with its ata well-marked diabetic condition of the urine, with its atin a few weeks; and it is probable that, if a different treatment for the liver complaint had been substituted for mercury and drinking largely of sea-water, Mr. I.'s life might have been prolonged, if not preserved.

Kensington, May 8 th, 1855.

\section{ON ASPARAGUS AS A DIURETIC.}

\section{By S. J. JEAFFRESON, M.D.}

I HAVE used a tincture of asparagus as a diuretic for sixteen or seventeen years, with increasing confidence in its usefulness and efficacy. I have thought it worth the notice of our Associstios at this particular period, because the time is now approaching at which any gentleman may easily make the experiment of its use. I use the following formula: Take of dried tops of asparagus, five ounces; proof spirit, two pints. Take of fresh tops of asparagus five pounds. Bruise and press out the juice; evaporate at a low temperature till reduced to one pint, and strain. Lastly, add a pint of rectified spirit. Mr. Baly, chemist, of Warwick, can furnish any person desirous of trying the tincture with a limited supply, and will be happy to make any quantity that may be ordered of him.

The peculiar odour communicated by this substance to the urine, in a remarkably short time, is perhaps as familiar to the laity as the profession. It was this fact that first led me to think that asparagus might constitute a valuable adjunct to our list of diuretics; if not indeed by virtue of any specific diuretic quality it possessed, at least by its power of directing other agents of acknowledged diuretic power to the kidneys.

On referring to such authorities as fell in my way, I found that, whilst some mentioned asparagus as a diuretic in general terms, without any specific reference to its medicinal administration, others omitted entirely to notice this plant, and some others denied its diuretic properties entirel5. It appeared to me evident that any deductions drawn on this subject had been founded entirely on its effects as an article of food, and not upon any direct experiments of its medicinal administration. The fallacy and uselessness of such deductions is sufficiently apparent; upon generalisations to vague, we might have discarded numerous of our best remedies as deleterious, innocuous, or useless.

Suffice it to say that, after some sixteen years' experience, I have found the tincture of asparagus a useful ad. junct to our diuretic remedies. In many cases, I have found it possessing direct diuretic properties when taken alone in water; but, in still more instances, I have found it most useful in promoting the diuretic properties of other drugs, as I conceive, by directing them at once to the kidneys. I have repeatedly in my own practice, as also in consultation, simply added from half a drachm to two drachms of tincture of asparagus to each dose of an unsuccessful diuretic, and found that copious diuresis was the result.

Mr. Baly informs me that the exact loss by weight in drying the plant is eleven parts out of twelve; in other words, that twelve parts by weight of the fresh shoots are only equal to one part of dried. I have not tried the infusion of the dry shoots, but should think them worthy of trial.

The tincture of asparagus presents the advantage of being capable of combination, so far as I know by experience, with every diuretic substance in use, be it from the animal, the vegetable, or the mineral kingdom.

Loarington, Yay 4th, 1855.

\section{PHRISCOPIC RHVLHW.}

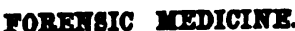

GLEANINGS FROM JOURNALS: WITH REMARKS.

CONYiction of A DENTIST For violatisa A PATIENT WHIE UNDER THE INFLUENCE OF ETHER INHALATION.

There are many instances on record of stupifying drugs having been employed for the purpose of facilitating the perpetration of the crime of rape, and in all legal codes special provision is made for such offenders; and the fact that their provis was unconscious does not in the smallest degree lessen the criminality of the deed. The discovery of the anæsthetic properties of ether and chloroform was, alas! too speedily followed by the application of these arents to criminal purposes. Both in this country and in France cases soon occurrel where, by the use of anresthetic vapours, not only ordinary thieves managed to expedite their robberies, but where professional men were so far left to themselves as to take advantage of the temporary helplessness of their patients and attempt to perpetrate a crime.

The British legislature, alive to the importance of promptly checking the use of anæsthetic agents as an adjuvant to crime, remedied the want in our criminal statutes by iuserting an act which made it a felony to employ chloroform for any such purpose. Since then, no convictions have taken place in this conntry for such offences; in France, however, one or two instances have been recorderl; and very recently in America, (in the town of Philadelphia), a dentist has been convicted of violating a patient while under the influence of ether. The case has excited great attention in America; and since the tria has taken place, the opinion las guined ground that the verdiet of the jury was not justified by the evidence presented. After carefni pertisal of the documents, we have come to the same conclusion, and we consider it our duty to present the case in snch detail as to enable our readers to judge for themselves. Country practitioners are often called unon to use chloroform for the extraction of teeth and other minor operations, where proper assistance is difficult to be had; and professional deutists, to our own knowledge, in such circumstanecs frequently dispense with the presence of a third party. This is wrong : and we trust that the following case mny show the necessity of such an arrangement during the exhibition of the anæsthetic as may save the reputation of practitioners, even though their patients should indulge in hallucinations similar to those which we are about to relate. We avail ourselves of the repurt extracted from the National Police Gazette of Philadelphia, and pub. lished in the Mredical Examiner for December 1854.

A young lady, of nnimpeachable character, who had for some time been engaged to be married, was accompanied by her betrothed to the house of an ancient and higbly respectable dentist, for the nurpose of having one of her teeth plugged. They arrived at his house about ten o'clock on a Friday morning. She entered the house alone, and after " $a$ few niuutes" spent in awaiting the exit of two other ladies, she was ushered into the operatiug room. What followed we give in her own words.

"I went to the oflice; took off my bonnet, and Dr. B. went to the washstand to wash his hands, and he askel me after the family; I took a seat on the operating chair; in a ferr minutes Dr. B.told me one of the men wanted to speak to him, and he gave me a book to read, and left the room; did not say what man; I supposed there were men there; he has a room in which the teeth are made; I believed those to be the men; Dr. B.'s family were out of town at that time; he said so, and the door was opened, and there was no furniture in the front room I don't know how long Dr. B. was absent; when he came back I was sitting in the operating chair; he went to the instrument case, and bergan with my tooth; the tooth was on the left side; he commenced operating on the tooth before he gave me ether; the operation was very painful; he snid he would either pat something in to destroy the nerve, or give me ether, leaving the choice to me; I told him I'd prefer taking ether; I didn't learn what he proposed putting into the tooth; he gave me ether on a small napkin, folded up; I felt very dizzy at first; I was cold and felt very numb; it increased upon me; I did not lose my consciousness of what was doing; I continued to breathe the ether; my eyes were closed; I closed them voluntarily; I did not try to open them for some time after; after he gave me the ether, he did not, as I remember, operate on my tooth; he felt my pulse several times; put his hand on my arm under wy 